Article

\title{
An Active Power Filter with Energy Storage and Double DC Conversion for Power Surge Compensation
}

\author{
Marcin Baszynski ${ }^{1, *}$, Kacper Sowa ${ }^{2}$ and Stanislaw Pirog ${ }^{1}$ \\ 1 Faculty of Electrical Engineering, Automatics, Computer Science and Biomedical Engineering, \\ Departament of Power Electronics and Energy Control Systems, AGH University of Science and Technology, \\ al. Mickiewicza 30, 30-059 Krakow, Poland; keiaspe@agh.edu.pl \\ 2 ABB Corporate Technology Center, Starowislna 13A st., 31-038 Krakow, Poland; kacper.sowa@pl.abb.com \\ * Correspondence: mbaszyn@agh.edu.pl
}

Received: 31 July 2020; Accepted: 4 September 2020; Published: 10 September 2020

check for updates

\begin{abstract}
This paper presents a single-phase power filter with an energy storage bidirectional DC/DC converter, both of which are equipped with separate capacitor-based DC links that provides good transient response and reduce energy storage capacity. The device is dedicated to the compensation of active power surges generated by nonlinear loads characterized by intermittent operation, where the operating time of a device in relation to the idle time is relatively short. As a compensated and filtered object, the single-phase spot welding machine with a thyristor current controller was assumed. In the case of such devices, the feeder has to be dimensioned for the peak loads, which increase the cost of installation-due to the fact that the used components have to be oversized. The proposed solution can produce measurable economic benefits by reducing the rated power necessary to energize periodically operating loads and improve the indicators of electrical energy quality. An elaborated control algorithm based on a switchable control structure provides a fast and good transient response. The work contains a comprehensive analysis of storage sizing, confirmed by simulation results performed in the Matlab and Simulink environment. Based on the analyses carried out, the laboratory model of the device was implemented and experimental verification performed.
\end{abstract}

Keywords: active power filter; energy storage; power surges; spot welders; power quality

\section{Introduction}

The crucial problems of a modern distribution system are limitation in power transfer and the quality of delivery. In some cases, the solution to the issue is the employment of power electronic devices [1-3]. It is performed by reactive power compensators and active power filters, compensating the reactive current component according to S. Fryze's or H. Akagi's definition $[4,5]$.

Nowadays, asymmetric and non-linear loads (consumers) running continuously or in cycles are fitted with reactive power compensators or active filters [6] which allow for the reduction of the voltage drop of the feeder line when surge currents flow and the current harmonics content increases. However, this solution does not reduce the peak current values of the feeder line and the transformer caused by surges of active power, due to the need to store a large amount of energy and need to inject it into the grid immediately $[7,8]$.

Alternatively, passive filtration can be used, however, it has many drawbacks, e.g., high inductance value for low frequencies, which cannot be miniaturized. Moreover, such filters are expensive and designed only for a selected frequency. In addition, the aging processes observed in passive components have a significant impact on the quality of filter operation. Regardless of their disadvantages, systems 
of this type are still used due to their reliability, and the ability to operate under high voltages and significant current values [9,10].

Active filters are used in contemporary solutions for asymmetric and non-linear systems [11-15]. Compared to passive filtration, they eliminate problems related to the possibility of resonance and there is no need to tune them to the frequency of the filtered harmonics. They can also remove a DC component from the current of the nonlinear receiver [11]. Regardless of their advantages, active filters (serial or parallel) do not solve the problem of intermittently running nonlinear loads, such as spot welders, crane drives, etc. In these types of loads, currents can reach high instantaneous values and be significantly distorted. An additional problem is the intermittent nature of operation: a system like a welder may work for tens of ms, and then be off for dozens of seconds. In such systems, an active filter minimizes the reactive power and limits the content of current harmonics, however, it does not reduce the value of the active component of the current. In the case of intermittent operation, where the operating time of a device in relation to the idle time is relatively short, the feeder (line, switchgear, transformer and so on) is dimensioned for the peak loads. Therefore, in order to ensure the correct operating conditions for other devices supplied from the same line, the short-circuit level of the network at the point of common coupling (PCC) must be sufficiently high.

Using an additional energy storage, drawing energy when there is no current consumption by the loads, and supporting their supply during their operation, enables a radical decrease in the feeder peak power value. It should be noted that providing correct conditions for the connection of this type of load to the feeder line is expensive since it forces the user to employ a terminal of a sufficiently high power.

The solution of the issue is the employment of a single-phase active power filter (APF) connected to an energy storage (ES) system whose control algorithm will enable the active power surge suppression in the feeder line (by limiting the variable power component value) $[16,17]$. Such a solution can produce measurable benefits by reducing the rated power necessary to feed periodically operating loads, and it improves the indicators of electrical energy quality. Furthermore, the developed method of active power surge compensation enables a flexible approach to the requirements concerning the rated power at the point at which the periodically operating loads with a high peak current value (apparent power) are connected.

The main contribution of this paper is the development of an active power filter integrated with energy storage, for a single-phase system. A similar integration has been proposed in [18], however, it addresses a three-phase system and renewables. Devices dedicated to the type of load selected in this paper are not well analyzed in the literature, due to relatively low active power, below $4 \mathrm{~kW}$. However, despite the small scale of the considered load and intermittent operation, the algorithm elaborated in this paper and energy balancing can pave the way for more detailed analysis in high power applications.

A similar issue is also occurring in shipboard microgrids, where more generators are kept online, operating far below their efficient point in order to compensate for the fluctuations caused by high dynamic loads and increase the reliability of the system [19]. Hence, the solution presented in this paper may significantly increase the efficiency of such power systems and reduce environmental pollution and fossil fuel consumption.

The simplicity of the used filter topology (H-bridge inverter) in comparison to, e.g., the five-level converter presented in [20], make them easier to implement and guarantee good compensation performance.

In comparison to [12], the elaborated switchable control algorithm is based on proportional-integral controllers (PI) and two control loops. In the developed structure, such a solution ensures a satisfactory transient response. The complexity of the analyzed phenomenon does not require sophisticated fieldprogrammable gate array (FPGA) based on adaptive power management algorithms, as shown in [21].

Moreover, separate DC conversion stages (two different DC links for an APF and ES) provide a good compensation dynamic and allow for the size reduction of filter storage. This feature is extremely important in single-phase circuits due to the limitation of double-line frequency components on DC 
link capacitors [22]. The presence of this component may cause distortion of the generated line current by the 3rd harmonic.

The time scale, as well as the nature of the compensated phenomenon, enable the use of electrolytic capacitors as an energy storage system in comparison to systems where battery energy storage systems are used [23,24].

Experiments are conducted in which supercapacitors are used as energy stores in compensators of the active power [25-27], however, the scale of the problem is different and relates to wind or solar power fluctuations.

The use of flywheel energy storage remains an alternative [28-31] in that solution. However, even due to the highest rate of current increase di/dt, the cost of installation is not justified in the analyzed case.

The high effectiveness of the solution presented in this article has been confirmed by simulations and laboratory experiments in which the current of a spot welder was compensated.

\section{Principle of Operation}

The idea of the system operation is presented in Figure 1. The system connected to the feeder line is composed of an active power filter, an energy store and a load switched on at irregular time intervals. In Figure 1 , the nature of the feeder line current $\left(I_{\text {line }}\right)$ and the load current $\left(I_{\text {load }}\right)$ is also marked. A thicker connection to the load symbolizes the requirements for the distribution equipment to handle such peak values of the load current.

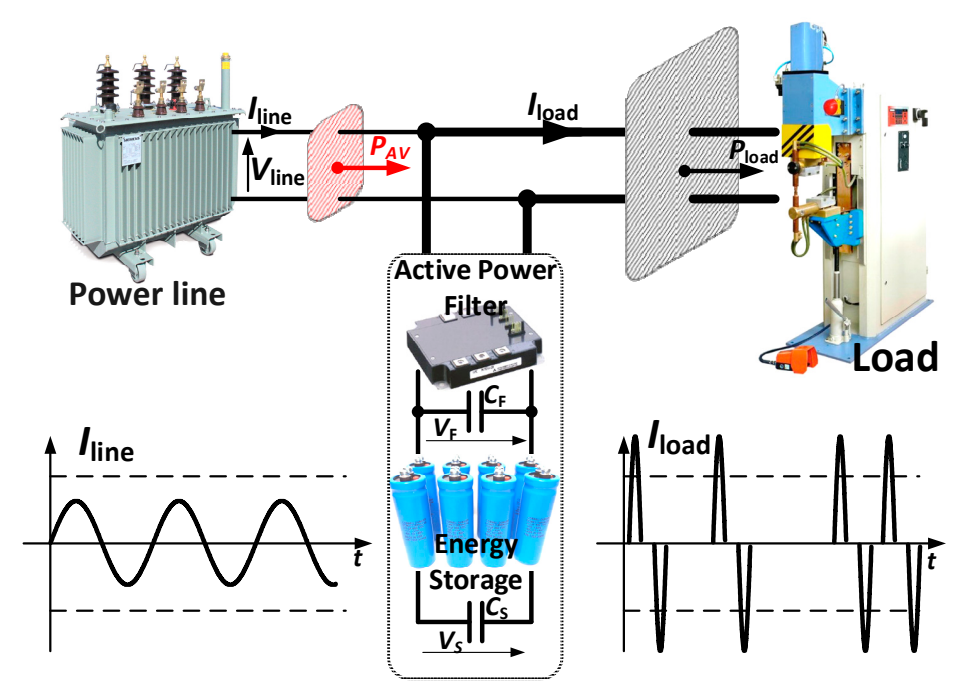

Figure 1. Single-phase active filter with energy storage-principle of operation diagram.

A typical APF is not capable of supplying and absorbing the active component of the current (in accordance with S. Fryze's power theory). Forcing an excessive or an insufficient flow causes an increase or a drop in the voltage in the filter capacitor $C_{\mathrm{F}}$, which must be constant over time for the correct operation of the filter. Due to that, in the proposed solution, an ES system is connected to the filter capacitor, whose function is to stabilize the voltage of the filter capacitor.

The system is composed of an APF with ES and naturally supports the compensation of the active and non-active components of the current injected by the load. In this case, the flow of the active component will not cause a change in the voltage $V_{\mathrm{F}}$, since the resulting fluctuations will be stored in the ES capacitor $C_{S}$.

The system aim is to continuously draw energy from the feeder line with a continuous flow of current Iline. Hence, the root mean square (RMS) value of this current is many times smaller than the RMS of the load current $\left(I_{\text {load }}\right)$. 
Under these conditions, the energy is not supplied to the load only from the line, but also through the APF with ES. Such an approach reduces the maximum power on the side of the feeder line, thus the feeder line can be designed for smaller rated currents.

Ensuring the continuous drawing of energy from the feeder line while the consumer runs intermittently means that the system must store energy during pauses in the operation of the load and return it when this intermittent load is turned on. Hence, the operation of the load is supported by an APF with ES and at the peak value the feeder line current is reduced by drawing the previously stored energy.

Assuming that the load operating time is many times shorter than its idle time, a properly selected sinusoidal current value, continuous and almost constant in time, can compensate an intermittent load that is many times greater.

Another advantage of the system is the mitigation of the welder negative impact on the feeder line by eliminating high-order current harmonics. This is achieved by the use of parallel active filter topology.

The turning on of the load, connected to the power line with the RMS voltage $V$ causes the flow of the active current component $I_{\text {load }}$, as illustrated in Figure 2a. However, the load current can also contain harmonics and reactive power (a non-active component according to $\mathrm{S}$. Fryze), hence, the APF has to be used as an interface between the ES system and the voltage source (power line).

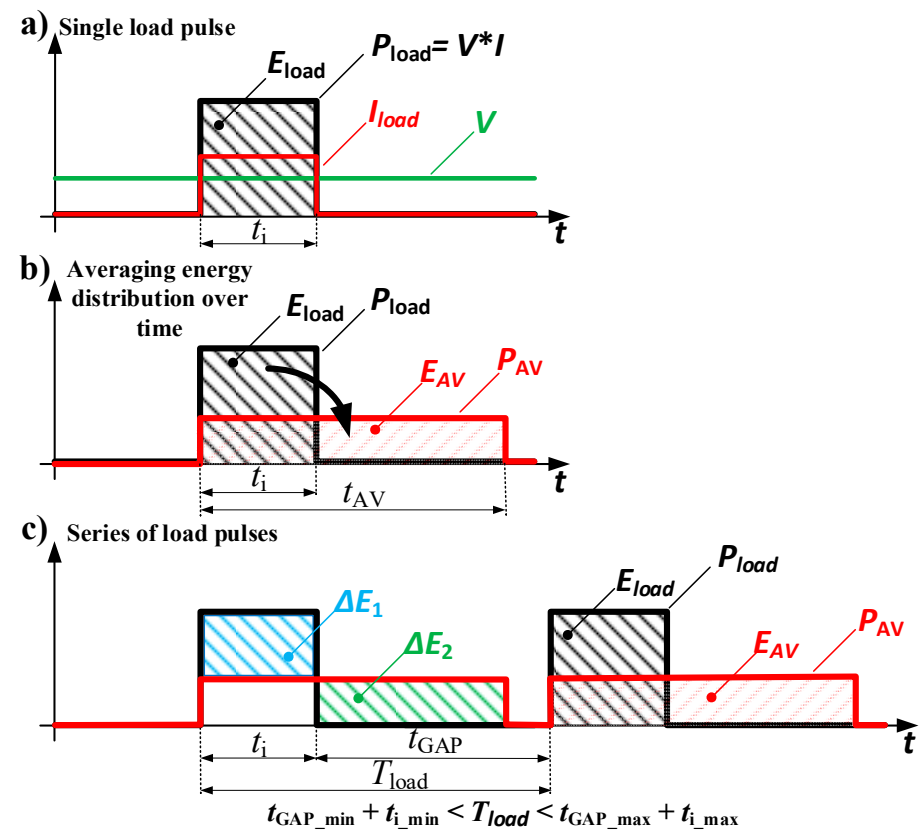

Figure 2. General idea of load pulse averaging by an active power filter (APF) with energy storage (ES): (a) single pulse of the load; (b) the averaging procedure-energy distribution over time; (c) series load pulse averaging over time; $t_{\mathrm{i}}$-load pulse duration, $t_{\mathrm{GAP}}$-interval between turning on of successive loads, $T_{\text {load }}$-quasi-period of load activation.

The product of the fundamental voltage harmonic RMS value $V$ and the active current component corresponds to the active power of the load $P_{\text {load }}$-the average value of the instantaneous power (Figure 2a). The area limited by the power curve is equal to the energy $E_{\text {load }}$ delivered by the source.

The essential function of the system is the compensation of active power surges/fluctuations generated during the turning on of the load. The idea of load pulse averaging is illustrated in Figure $2 b$.

The amount of energy $E_{\text {load }}$ delivered from the source to the load, during its single activation (pulse), lasting for time $t_{\mathrm{i}}$, is described by the dependence (1):

$$
E_{\text {load }}=P_{\text {load }} \cdot t_{\mathrm{i}}
$$


The reduction of $P_{\text {load, }}$ within a period $t_{\mathrm{i}}$ to the power level of $P_{\mathrm{AV}}$ (Figure $2 \mathrm{~b}$ ), requires a proportional increase in time, during which the energy is transferred from the source $\left(t_{\mathrm{AV}}\right)$. Keeping the energy balance through the system means that the surface areas (energies) $-E_{\text {load }}$ and $E_{\mathrm{AV}}$-should be equal. The pulse averaging process is illustrated in Formula (2):

$$
P_{\text {load }} \cdot t_{\mathrm{i}}=P_{\mathrm{AV}} \cdot t_{\mathrm{AV}} \Rightarrow P_{\mathrm{AV}}=P_{\text {load }} \frac{t_{\mathrm{i}}}{t_{\mathrm{AV}}}
$$

where $P_{\mathrm{AV}} \cdot t_{\mathrm{AV}}=\mathrm{E}_{\mathrm{AV}}$ is equivalent to $E_{\text {load }}$ energy consumed by the load operating with $P_{\mathrm{AV}}$ power during the period $t_{\mathrm{AV}}$.

General assumptions are:

$$
P_{\mathrm{AV}} \ll P_{\text {load }} \wedge t_{\mathrm{i}} \ll t_{\mathrm{AV}}<t_{\mathrm{GAP}}
$$

The interval between successive load turning on $\left(t_{\mathrm{GAP}}\right)$, as well as the duration of a single turn-on pulse $\left(t_{\mathrm{i}}\right)$ and its power $\left(P_{\text {load }}\right)$, are predefined by the technological process. The sum of $t_{\mathrm{i}}+t_{\mathrm{GAP}}$ determines the "quasi-period" $\left(T_{\text {load }}\right)$-during which load activation may occur.

Selected by the system according to (2), the value of $P_{\mathrm{AV}}$ during time interval $t_{\mathrm{AV}}\left(t_{\mathrm{AV}}<T_{\text {load }}\right)$ should ensure the correct distribution of the $P_{\text {load }}$ pulse before the next one occurs, without increasing the power value of the source during the period $T_{\text {load }}$, as illustrated in Figure 2c.

The analysis of the technological process allows us to determine the time interval's characteristic for a given technological line: minimum and maximum duration of the $T_{\text {load }}$ period, within which load activation should occur, as well as the limit values of a single load pulse duration $t_{\mathrm{i}}$-which is a multiple of the full number of voltage source periods.

The system must ensure correct operation with the longest $t_{i \_m a x}$ pulses (load turned on for the maximum time) which are repetitive within the shortest period between successive load turning on $T_{\text {load_min }}$ (maximum energy and power of the source), as well as in the opposite case- the shortest $t_{i \_ \text {min }}$ and $T_{\text {load_max }}$ (important in the context of control system dynamics). Both cases are depicted in Figure 3.

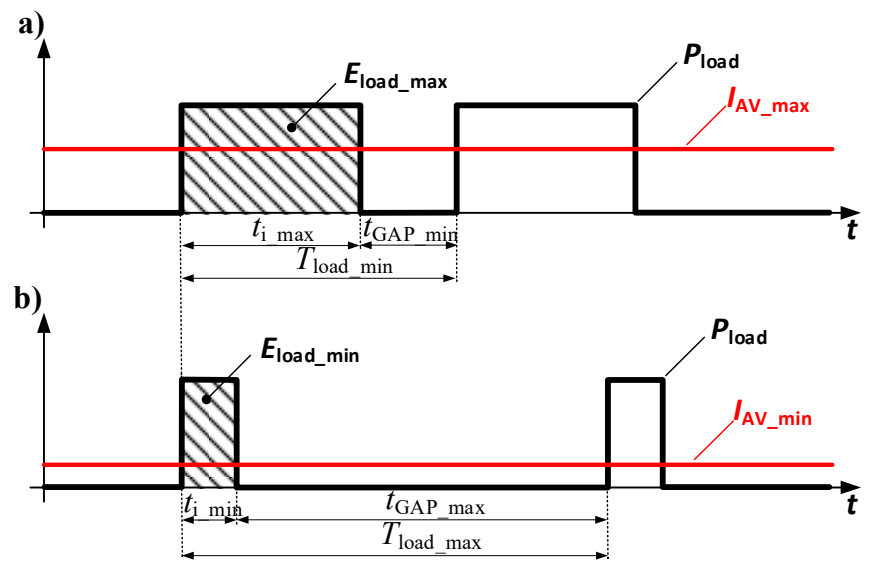

Figure 3. Boundary load conditions with a constant value of power: $P_{\text {load }}$ : (a) operation with maximum duration of the load turn-on pulse $t_{\text {i_max }}$ and minimum interval $T_{\text {load_min }}$ between successive load pulses (maximum of the energy); (b) operation with minimum duration of the load pulse $t_{\mathrm{i} \_\min }$ and maximum interval $T_{\text {load_max }}$ between successive load pulses; $I_{\mathrm{AV} \_ \text {min }} / I_{\mathrm{AV} \_m a x}$-the $\mathrm{min} / \mathrm{max}$ average values of the line current which ensure electrical energy balance in the APF + ES circuit.

The determination of the maximum load power $\left(P_{\text {load_max }}\right)$ and the maximum duration of a single load pulse $\left(t_{i \_ \text {max }}\right)$ leads to the calculation of the maximum value of the reduced source power $P_{\mathrm{AV} \_ \text {max }}$ 
(according to Formula (2)), obtainable for the assumed type of load in the assumed shortest time between impulses $T_{\text {load_min }}(4)$ :

$$
P_{\text {AV_max }}=P_{\text {load_max }} \cdot \frac{t_{\text {i_max }}}{T_{\text {load_min }}}
$$

where $P_{\text {load_max }}$ is the maximum value of the load power; $P_{\mathrm{AV} \_ \text {max }}$ is the maximum value of the source power; $t_{i \_m a x}$ is the maximum duration of the load turnon pulse and $T_{\text {load_min }}$ is the minimum interval between the successive load pulses. Formula (4) describes the most critical case when the system is exposed to boundary conditions and has the shortest time $\left(t_{\mathrm{GAP}} \mathrm{min}\right)$ to recover energy before the load is turned on again, as illustrated in Figure 3a.

The operation of the system requires the storage of the $\Delta E_{1}$ portion of the energy in the structure of the ES system (Figure 2c). The $\Delta E_{1}$ energy is released from the system when the load is turned on. It results in the intended effect of source power reduction. After the load is turned off, the energy loss $\Delta E_{1}$ is supplemented by the value $\Delta E_{2}$ with constant power (the system maintains the constant value of the current $I_{\mathrm{AV}}$ ), thus the energy balance of the system is satisfied (5):

$$
\Delta E_{2}=\Delta E_{1}
$$

The assumed value of $P_{\mathrm{AV}}$ ensures that when $t_{\mathrm{AV}}<T_{\text {load }}$ the energy $\Delta E_{1}$ will be supplemented before the load is turned on again, hence the system will be fully prepared for the next switching on of the load.

According to dependence (5), the minimum amount of stored energy $E_{\mathrm{S} \_ \text {min }}$ should be greater than $\Delta E_{1}$ for the assumed maximum power of the receiver $\left(P_{\text {load_max }}\right)$, operated with the maximum duration of a single pulse $\left(t_{i_{\text {_max }}}\right)$ and the minimum interval between successive pulses $\left(t_{\mathrm{GAP} \_ \text {min }}\right)$. The minimum value of the energy stored in the system $E_{\mathrm{S}_{-} \min }$, including losses $\Delta E$, was determined by the dependence (6):

$$
E_{S \_ \text {min }}>P_{\text {load_max }} \cdot t_{\text {i_max }}+\Delta E \Rightarrow E_{\text {S_min }}>E_{\text {load_max }}+\Delta E
$$

The implementation of the presented assumptions requires an APF connection with the ES system. The operation of the proposed system does not affect the current (power) of the load, however, it significantly reduces the current of the source.

The function of the APF is to eliminate the harmonics and the reactive current component, while the role of the ES system is to limit the active power fluctuations when the load is turned on. This is done by limiting the active current component as a result of energy transfer from or to the ES system.

The value of filter capacity $C_{\mathrm{F}}$ was determined, as a result of the transformation of the dependence describing the energy stored by the capacitor. The voltage across the capacitor during operation with a maximum assumed power $P_{\text {load_max }}$ within one period of source voltage should not fall below the level which provides the correct operation (7):

$$
E_{\mathrm{F} \_ \text {max }}-E_{\text {load_max }(1)} \geq E_{\mathrm{F} \_ \text {min }}
$$

where:

$$
\begin{gathered}
E_{\mathrm{F} \_ \text {max }}=\frac{1}{2} C_{\mathrm{F}} V_{\mathrm{F} \_ \text {max }}^{2} \\
E_{\mathrm{F} \_ \text {min }}=\frac{1}{2} C_{F} V_{\mathrm{F} \_ \text {min }}^{2} \\
E_{\text {load_max }(1)}=P_{\text {load_max }} \cdot T=\frac{P_{\text {load_max }}}{f_{\mathrm{i}}} \\
V_{\mathrm{F} \_\min }=V_{\mathrm{F} \_\max }-\Delta V
\end{gathered}
$$


where $E_{\mathrm{F} \_ \text {max }}$ is the maximum energy level stored in the capacitor $C_{\mathrm{F}} ; E_{\mathrm{F} \_ \text {min }}$ is the minimum energy level stored in the capacitor $C_{\mathrm{F}} ; E_{\text {load_max(1) }}$ is the maximum level of energy consumed by the load operating at maximum power $P_{\text {load_max }}(1 \mathrm{~kW})$ during one period of source voltage; $T=1 / f_{\mathrm{i}}, f_{\mathrm{i}}(50 \mathrm{~Hz})$ is the frequency of the source fundamental harmonic; $V_{\mathrm{F}_{-} \max }(500 \mathrm{~V})$ is the maximum (reference) value of the voltage on $C_{\mathrm{F}} ; V_{\mathrm{F}_{-} \text {min }}$ is the minimum value of the voltage on $C_{\mathrm{F}} ; \Delta V(100 \mathrm{~V})$ is the assumed voltage drop across the capacitor $C_{\mathrm{F}}$.

As a result of substituting (8)-(11) into (7), the expression (12) was obtained to determine the minimum value of the capacitance of the filter:

$$
C_{\mathrm{F}} \geq \frac{P_{\text {load_max }}}{f_{\mathrm{i}}\left(V_{\mathrm{F} \_ \text {max }} \cdot \Delta V-\frac{\Delta V^{2}}{2}\right)}=\frac{1000}{50\left(500 \cdot 100-\frac{100^{2}}{2}\right)}=444 \mu \mathrm{F}
$$

The key issue in the presented system is the selection of the energy storage capacitance value $C_{S}$. Increasing the amount of stored energy (e.g., through the use of a larger capacitor) allows for the use of a slower voltage controller, thus a better averaging over time of the generated source reference current.

The energy accumulated in the storage capacitor $C_{S}$ should compensate the energy losses in the $C_{\mathrm{F}}$ during the load operation as well as the losses in the $\Delta E$ elements, without changing the value of the generated (compensated) source current. Too small a value of $C_{S}$ forces an operation with a higher source current (or larger fluctuations of its RMS value).

In the case of a $C_{S}$ capacitor, the maximum operating voltage $V_{S_{-} \max }$ cannot exceed the value of the filter maximum voltage $V_{\mathrm{F}_{-} \max }$. The acceptable minimum of $\mathrm{ES}$ operating voltage $V_{\mathrm{S}}$ is equal to $1 / 2$ of the nominal value. This means that the capacitor is charged by $25 \%$. Discharging the capacitor below this value further reduces the operation of the system (the transfer of energy from the ES system to the filter capacitor is ineffective).

The selected value of the $C_{S}$ guarantees the energy reserve for the compensation of the assumed number of load impulses before the $C_{S}$ is discharged to the minimum level.

The value of the $C_{S}$ was determined in a similar way to $C_{F}$. During the load compensation, the amount of stored energy should not fall below the level guaranteeing the correct operation of the ES system. The value was calculated for the boundary conditions of the load, operating with a maximum power $P_{\text {load_max }}$ and turned on for the longest $t_{i \_ \text {max }}$ (which is a multiple of the total number of source voltage periods $\left.t_{\text {i_max }}=n_{\max } \cdot T\right)$ :

$$
E_{\mathrm{S}_{-} \max }-E_{\mathrm{load}_{\max (\mathrm{n})}}>E_{\mathrm{S}_{-} \min }
$$

where

$$
\begin{aligned}
& E_{\text {S_max }}=\frac{1}{2} C_{S} V_{S_{-} \max }^{2} \\
& E_{\text {S_min }}=\frac{1}{2} C_{S} V_{S_{-} \text {min }}^{2}
\end{aligned}
$$

where $E_{S_{-} \max }$ is the maximum energy stored in the ES capacitor $C_{S} ; E_{S_{-} \min }$ is the minimum energy level stored in the capacitor $C_{S} ; E_{\text {load_max (n) }}$ is the maximum energy consumed by the load during " $n$ " periods of source voltage; $V_{S_{-} \max }$ is the maximum (reference) value of the voltage in $C_{S} ; V_{S_{-} \min }$ is the minimum value of the voltage in $C_{S}$.

The energy transferred from the source to the load during a single turn on for $n$ periods of the source voltage can be calculated by (16):

$$
E_{\text {load }_{\max (\mathbf{n})}}=t_{\text {i_max }} \cdot P_{\text {load_max }}=n_{\max } \cdot T \cdot P_{\text {load_max }}=n_{\max } \cdot E_{\text {load }} \max (1)
$$

where $n_{\max }$ is the maximum number of load operation periods with maximum power $P_{\text {load_max }}$ during one switch-on cycle; $E_{\text {load_max(1) }}$ is the maximum energy consumed by the load during "1" period of source voltage. 
The substitution of (14) and (15) into (13) leads to dependence (17) which enables the calculation of the minimum $C_{S}$ capacity. The selected value guarantees that during a single turn on of the load for maximum time $t_{\text {i_max }}(6 \times 20 \mathrm{~ms})$, operated with maximum power $P_{\text {load_max }}(1 \mathrm{~kW})$, voltage across a capacitor will not fall below the minimum level $V_{S_{-} \min }=1 / 2 V_{S_{-} \max }=200 \mathrm{~V}$.

$$
C_{S}>2.67 \frac{P_{\text {load_max }} \cdot t_{\text {i_max }}}{V_{S \_\max }^{2}}=2.67 \frac{1000 \times 120 \mathrm{~ms}}{400^{2}}=2 \mathrm{mF}
$$

\section{Simulation Results}

The system preliminary test was carried out in a Matlab and Simulink environment (SimPowerSystems library). A block diagram of the circuit is illustrated in Figure 4.

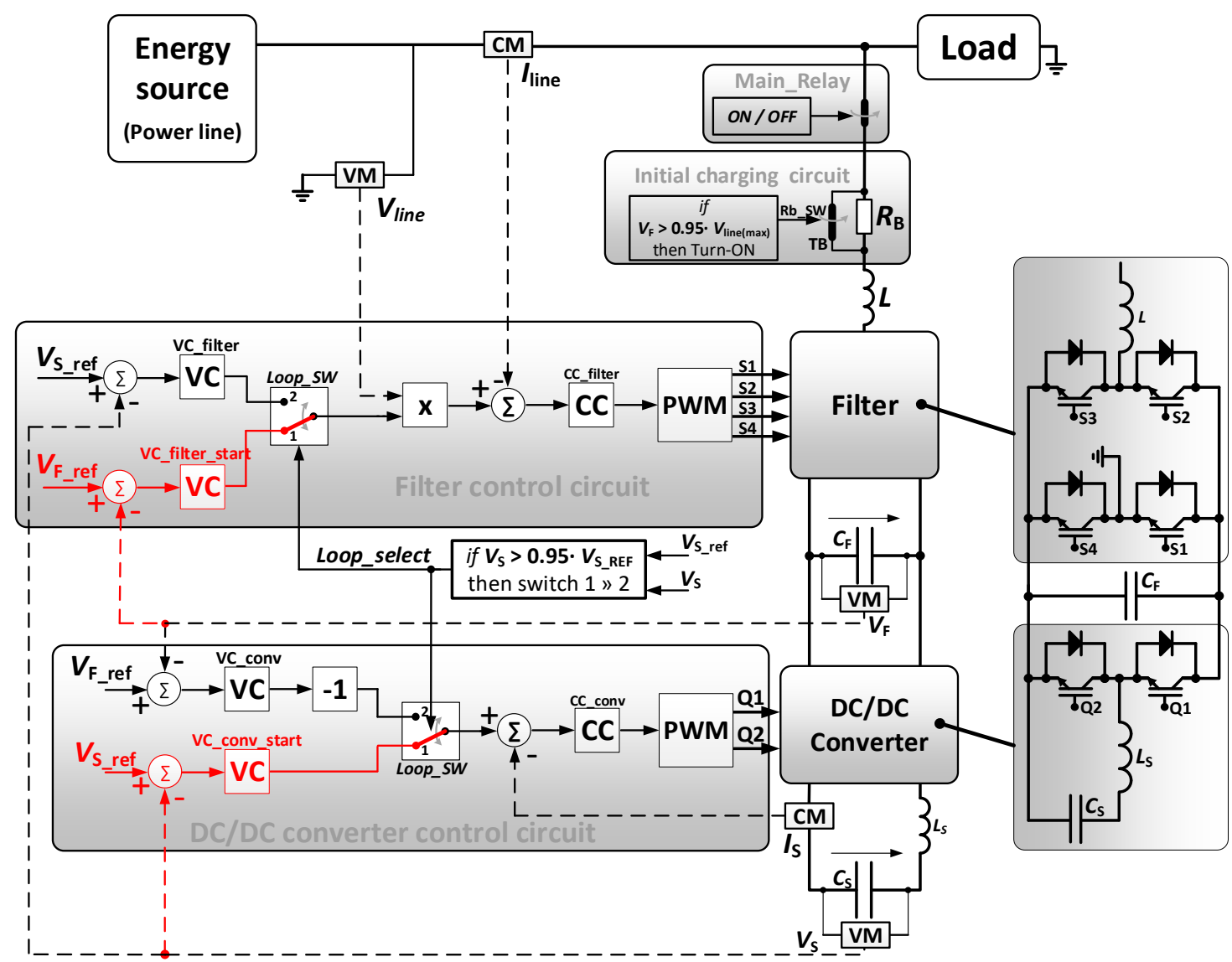

Figure 4. Block diagram of the model used during simulations in the Matlab and Simulink environmentsections used during startup are marked red, where: CC—current controller, VC-voltage controller, $\mathrm{VM}$-voltage measurement sensor, $\mathrm{CM}$-current measurement sensor.

The analyzed APF is a voltage inverter in the H-bridge topology with current waveforms shaped by pulse width modulation (PWM). The energy storage DC/DC converter is composed of Q1 and Q2 switches as well as a $C_{S}$ capacitor.

The tested device is connected in parallel between the load (spot welder modeled as a series connection of $R L$ elements, where $R<<X_{\mathrm{L}}$ and a thyristor current controller) and the feeder line, modeled as an AC source with an inductance $(100 \mu \mathrm{H})$ and resistance $(3 \mathrm{~m} \Omega)$ connected in series. The values are determined using the data sheet of a $15 / 0.4 \mathrm{kV}$ three-phase distribution transformer.

The switching frequency is equal to $10 \mathrm{kHz}$, while the entire model is executed at a step of $2 \mu \mathrm{s}$ $(500 \mathrm{kHz})$. 
The operation of the device is controlled by two cascade control loops, depicted in Figure 4 (PI controllers are used). The structure of a single control loop consists of an internal, fast current controller, CC, and two external voltage controllers, VC, one of which is used during the startup procedure and the other during the normal mode of operation. Current controllers are common for both phases of the system operation.

Different dynamics (sizes) of controlled storages $C_{\mathrm{F}}<<C_{\mathrm{S}}$ require quick controller parameter changes as well as input signal (feedback) in order to avoid the transient phenomenon in controlled signals. It is implemented by Loop_SW when appropriate conditions are fulfilled.

During startup, the filter control loop stabilizes voltage across filter capacitor $C_{\mathrm{F}}$, however, in normal operation mode, the dynamics of this control loop should be low in order to ensure proper compensation of the load current. Similarly, once the DC/DC converter control loop is stabilizing voltage across $C_{S}$, then in normal operation mode it is responsible for the control of voltage across the considerably smaller filter capacitor $C_{\mathrm{F}}$.

The current controllers are characterized by a large (in comparison to voltage controllers) proportional gain $K_{\mathrm{p}}(50 \div 130)$, which is necessary to ensure proper dynamics, while the integration time is selected from the interval $1 \div 5 \mathrm{~ms}$.

In the case of the voltage controllers, the values of the proportional gain do not exceed one $(0.03 \div 0.22)$ and the integration times are selected from the interval $10 \div 20 \mathrm{~ms}$. The small value of the proportional gain $\left(K_{\mathrm{p}}<1\right)$ in the structure of the first filter control loop ensures adequate attenuation of the third harmonic during the startup in the generated waveform of the source current.

Due to the load power pulse averaging, the settings of the voltage controller (VC_filter) used during normal operation are the most important. The controller is characterized by a negligible small proportional gain $\left(K_{\mathrm{p}}=0.03\right)$, which guarantees the stabilization of the $V_{\mathrm{S}}$ voltage within the assumed range, without the possibility of exceeding the acceptable safety levels.

The integration time of the voltage controller (equal to $40 \mathrm{~s}$ ), is adopted on the basis of the assumed multiple interval between successive load turn ons ( $t_{\mathrm{GAP}}$ max $\left.=20 \mathrm{~s}\right)$.

Selected in such a way, the value ensures an appropriate distribution (averaging) of the load pulse over time. The use of a slow controller is possible only due to a sufficiently large energy store (a $C_{\mathrm{S}}$ capacitor). The capacity of the storage must provide an energy supply equal to at least one load pulse $t_{i \_ \text {max }}$, with the assumed power.

In Figure 5, the block diagram of the used series PI controller topology is depicted, based on [32,33]. Detailed controller parameter specifications can be found in Appendix A, Table A1. The initial values are determined using PID Tuner [34], which were then tuned during the experiment.

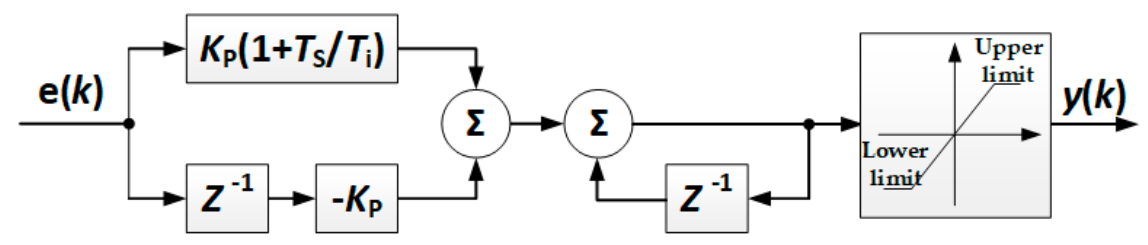

Figure 5. The block diagram of the series proportional-integral (PI) controller, where: $e(k)$-the control error signal, $y(k)$ - the controller output signal, $K_{\mathrm{P}}$ 一the proportional gain, $T_{\mathrm{S}}$ 一the sample time, $T_{\mathrm{i}}$ - the integral time constant.

Figure 6 presents the simulation results of the feeder line and the DC/DC converter currents $\left(I_{\text {line }}, I_{\mathrm{S}}\right)$ and the voltages across the filter and converter capacitors $\left(V_{\mathrm{F}}, V_{\mathrm{S}}\right)$, recorded during the developed model startup. After approximately just $1.4 \mathrm{~s}$, the system reaches full ability to operate under load conditions. The startup procedure is initiated by activation of the Main_Relay. 

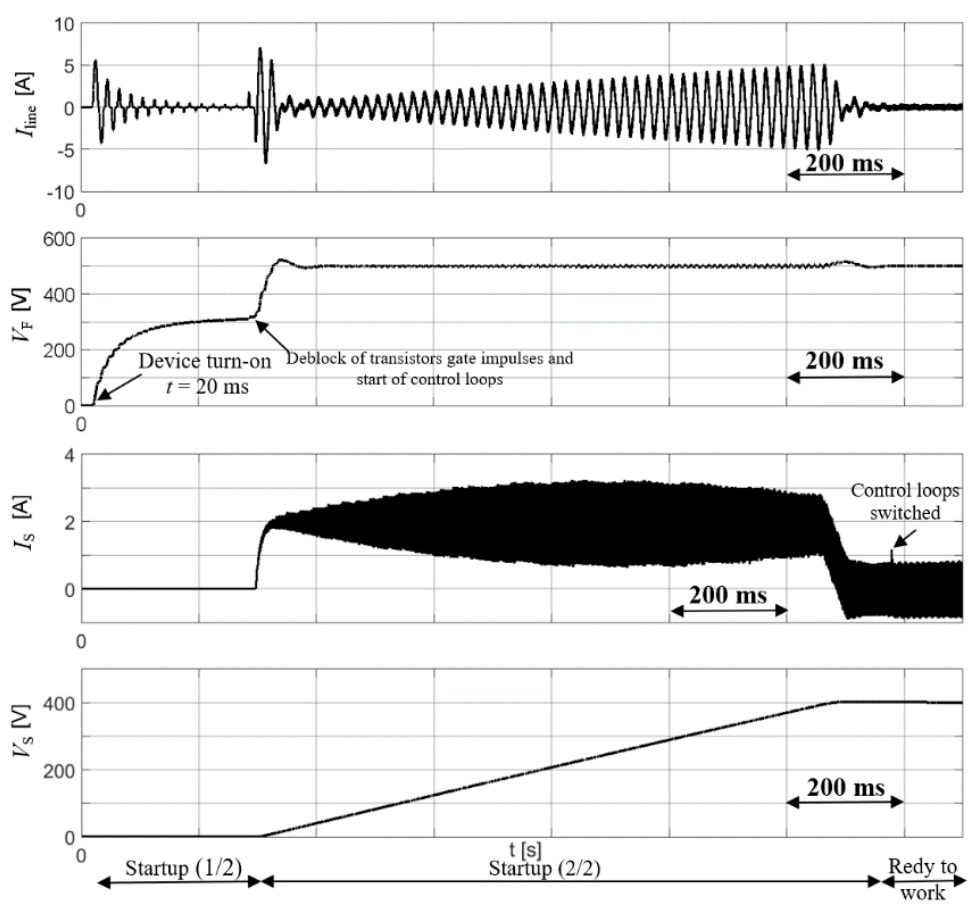

Figure 6. APF with ES startup procedure-simulation results.

The first startup stage- "StartUp $1 / 2$ " - consists of the preliminary charging of the capacity $\mathrm{C}_{\mathrm{F}}$. The capacitor is charged by the diodes included in the insulated gate bipolar transistor (IGBT) structure. The value of the charging current is limited by a resistor $\mathrm{RB}(50 \Omega)$ installed on the input of the filter.

After the voltage $V_{\mathrm{F}}$ reaches a steady value, the $R_{\mathrm{B}}$ resistor is bypassed by the $T_{\mathrm{B}}$ switch (relay). If the voltage of the feeder line is not distorted, the voltage on the capacitor will amount to approximately $325 \mathrm{~V}$. The TB relay is activated when $V_{\mathrm{S}}>310 \mathrm{~V}\left(V_{\mathrm{S}}>0.95 V_{\text {line (MAX) }}\right)$.

During the second stage of "StartUp 2/2" (Figure 6), the impulses controlling the transistors in the filter and the DC/DC converter are unblocked and the control structure is activated.

The purpose of the first control structure (comprising the VC_filter_start and the CC_filter, Figure 4) is to stabilize the voltage on the filter capacitor $C_{\mathrm{F}}$ at the reference level of $500 \mathrm{~V}$. This is achieved by developing the appropriate reference of the feeder line current. During this phase, the filter acts as a sinusoidal current rectifier.

Simultaneously with the operation of the filter control, the DC/DC converter control system (which consists of VC_conv_start and CC_conv, Figure 4) is activated. Its function is to stabilize the output voltage of the converter capacitor $V_{\mathrm{S}}$ at the reference level $400 \mathrm{~V}$. The capacitor $C_{\mathrm{S}}$ is charged by the converter using the energy stored in the filter capacitor $C_{F}$ (the buck mode of operation). This causes a drop in the voltage $V_{\mathrm{F}}$, which is compensated by the filter control circuit. The value of the feeder line reference current has to be increased correspondingly.

In the analyzed case, the current $I_{\mathrm{S}}$, which charges the capacitor $C_{\mathrm{S}}$, is limited to $2 \mathrm{~A}$ (the value selected only for the startup $0 \div 2 \mathrm{~A}$ ). The maximum value of the feeder current during the startup is limited to $\pm 7 \mathrm{~A}$. This is achieved by selecting the appropriate saturation value of the voltage controllers.

The startup process ends when the voltage of the energy store exceeds $380 \mathrm{~V}\left(V_{\mathrm{S}}>380 \mathrm{~V}\right)$. Then, the final control system is launched (by means of the Loop_SW switches triggered by the Loop_Select signal).

The waveforms of the currents and voltages of the feeder line are recorded when the system is compensating an actuated load within a wide time horizon ( $30 \mathrm{~s})$. They are shown in Figure 7a (enlarged in Figure 7b). The line current is sinusoidal in and in phase with the line voltage, while the actuation of the load no longer impacts on the line current value. 


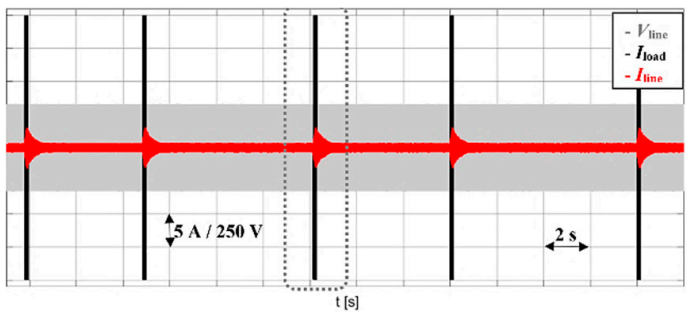

(a)

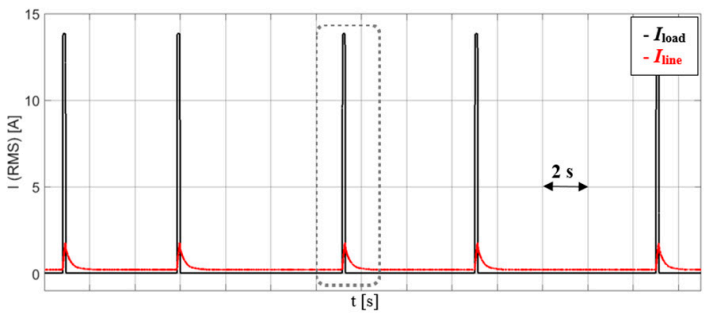

(c)

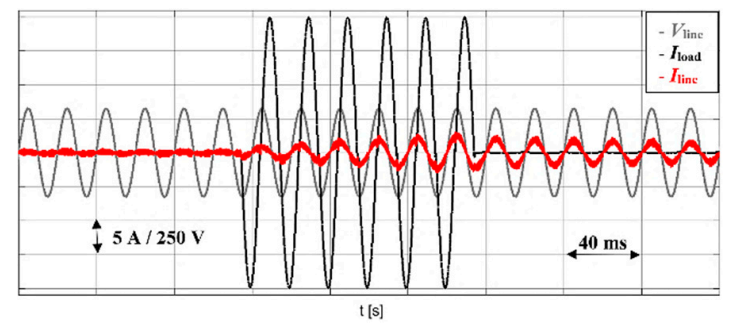

(b)

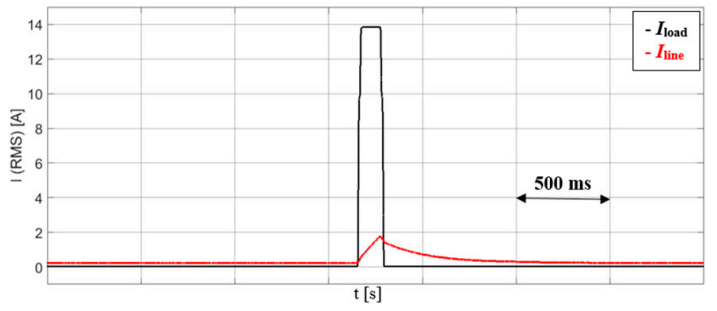

(d)

Figure 7. Waveforms of line and load current during compensation/filtration of the load: (a) instantaneous values of $V_{\text {line }}$ and $I_{\text {line }}$ in a wide time horizon (30 s) nlarged in (b); (c) calculated root mean square (RMS) values of line and load current in a wide time horizon (30 s) enlarged in (d).

The effective operation of the system is confirmed by the RMS waveforms of the load $\left(I_{\text {load }}\right)$ and line $\left(I_{\text {line }}\right)$ currents when the filter with the energy storage is working, as shown in Figure 7c (enlarged in Figure 7d).

The system operation limits the sudden increases of line current RMS value caused by the actuation of the load, as is clearly visible in the enlarged fragment shown in Figure 7d. The RMS value of the current forced by the load is approximately $14 \mathrm{~A}$. The elaborated solution significantly reduced it to the level of $2 \mathrm{~A}$.

\section{Experimental Results}

The designed and constructed spot welder, as well as active power filter with an additional energy storage DC/DC converter, are depicted in Figure 8. Both of them are based on electrolytic capacitors. Detailed system specifications can be found in Appendix A, Table A2.

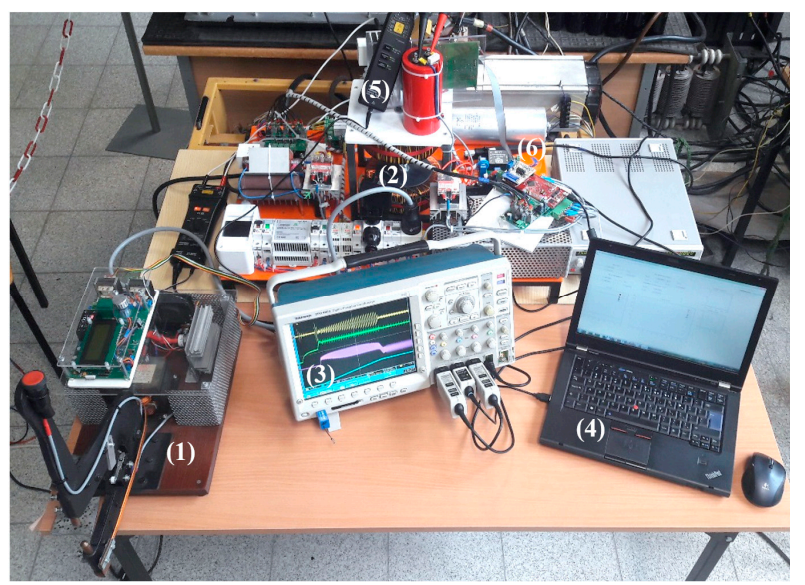

Figure 8. Developed laboratory stand used during experiment, where: (1) load—spot welder with thyristor current controller; (2) active power filter with energy storage; (3) oscilloscope TEK DPO4054; (4) PC computer with GUI interface; (5) HV Differential Probe TEK P5205A, (6) Current Probe TEK TCP0020. 
Construction of the welder requires a step-down transformer and two thyristors connected antiparallel on the primary transformer side. In the analyzed case, the welding current was about $600 \mathrm{~A}$ and galvanized steel plates $(0.25 \mathrm{~mm}$ thickness) were welded.

The welder current controller enables smooth adjustment of the thyristor firing angle, moreover, the welding time $\left(t_{\mathrm{i}}\right)$ can also be adjusted.

During the laboratory tests, an analysis of the steady and dynamic states was performed. The elaborated algorithms of the control concepts were verified in the full range of the load.

The system startup process was the same as that presented in the simulation results in Figure 6. The recorded oscillogram with marked startup phases is presented in Figure 9. After approx. $1.5 \mathrm{~s}$, the device was ready to work.

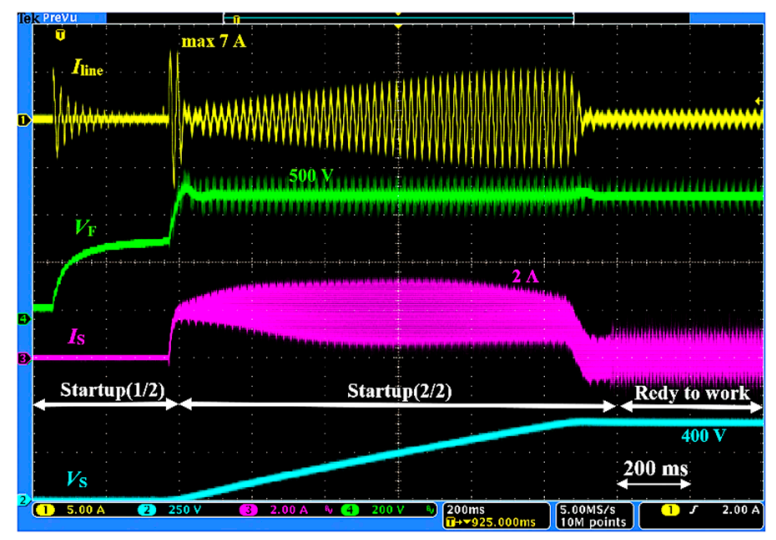

Figure 9. APF with ES startup procedure, experimental results corresponding to simulation result presented in Figure 6.

The working conditions for which this system was designed are shown in Figure 10a. The drawing shows the waveforms of the feeder line and load currents as well as the voltage in the DC/DC converter circuit. The waveform recording duration was limited to $100 \mathrm{~s}$. A compensated spot welder was incidentally actuated with a constant welding duration time $\left(t_{\mathrm{i}}=6 \times 20 \mathrm{~ms}\right)$ and a constant thyristor firing angle $\alpha=70^{\circ}$, as illustrated in Figure 11 (load operated with a maximum power $P_{\text {load_max }}$ and turned on for the longest assumed time $t_{i \_\max }$ ).

As a result of the system operation, the maximum value of the feeder line current did not exceed $4 \mathrm{~A}$, while the peak value of the current forced by the load was equal to approx. $22 \mathrm{~A}$.

This means that the peak current of the line, and hence the requirements for the components supplying energy to the compensated load (e.g., the conductor cross section), was reduced by over $80 \%$.

The non-repeatability of the shape of the recorded welding currents (e.g., the differences between the maximum values regardless of maintaining a constant welding angle) are due to phenomena occurring between electrodes (the burning out of oxides and contamination, uneven contact pressure, etc.) [16].

Figure 10b is a detail of Figure 10a. It shows two subsequent actuations of the load occurring at different time intervals. In the presented case, the load is actuated at an interval shorter than $5 \mathrm{~s}$, but the system is still able to restore the voltage $V_{\mathrm{S}}$ within approx. $1 \mathrm{~s}$ and retain its compensation ability. This proves that the assumed time interval $\left(T_{\text {load_min }}=5 \mathrm{~s}\right.$ ) between subsequent actuations of the load ensures the appropriate safety margin for restoring the voltage $V_{\mathrm{S}}$ even when the welding time is increased.

Based on the waveforms of the feeder line current and load current shown in Figure 10a,b, the RMS values of these signals were determined in accordance with a true RMS algorithm [35]. A graph of the waveforms produced in the analyzed time horizon is presented in Figure 10c (zoomed-in Figure 10d). 


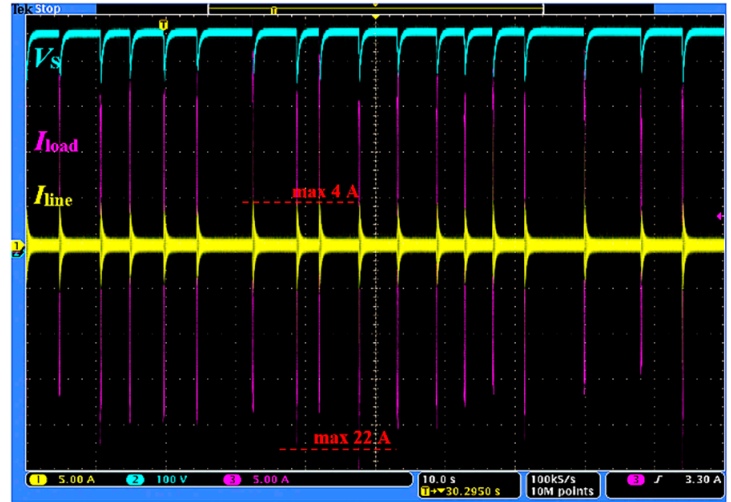

(a)

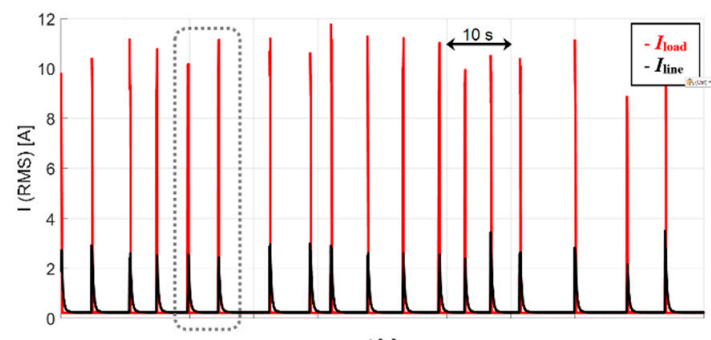

(c)

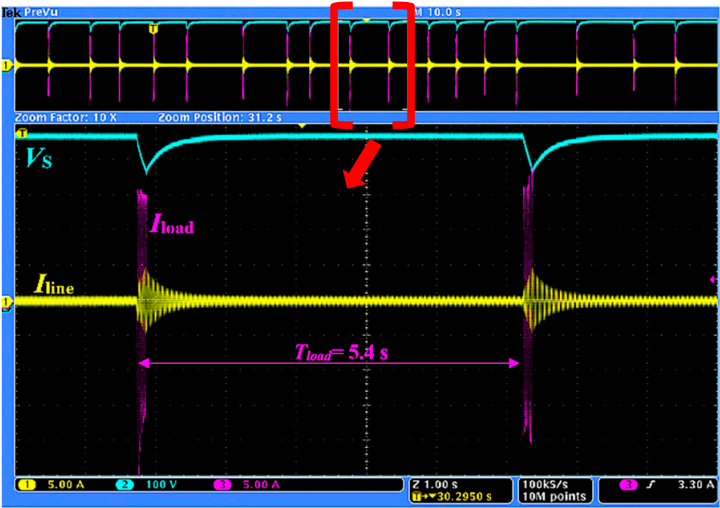

(b)

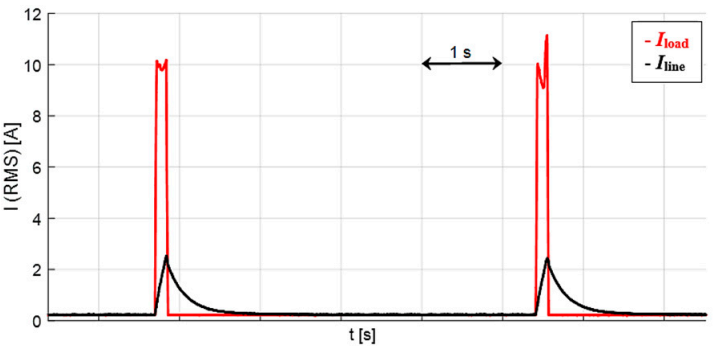

(d)

Figure 10. Measured $I_{\text {line, }} I_{\text {load }}$ currents, line voltage $V_{\text {line }}$ and DC/DC converter voltage $V_{\mathrm{S}}$ during compensation of the load-spot welder turned on randomly for six periods of line voltage $(6 \times 20 \mathrm{~ms})$ in a wide time horizon (100 s), firing angle of thyristors equal to $\alpha=70^{\circ}$ : (a) instantaneous values of measured signals—a zoomed-in view in (b); (c) calculated RMS values of measured signals in a wide time horizon (100 s) — enlarged in (d).

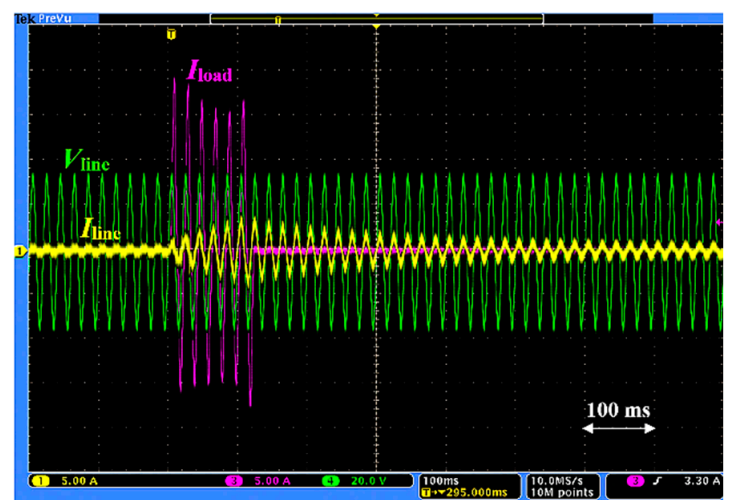

(a)

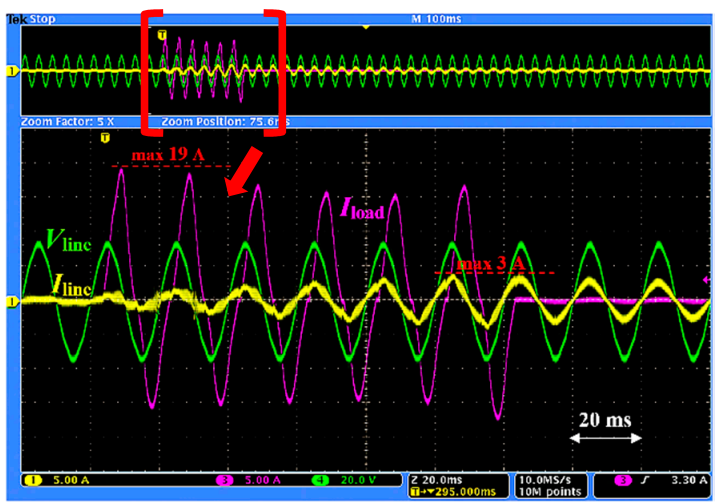

(b)

Figure 11. Measured $I_{\text {line, }}, I_{\text {load }}$ currents and line voltage $V_{\text {line }}$ during compensation of the load-spot welder, turned on for six periods of line voltage $(6 \times 20 \mathrm{~ms})$, firing angle of thyristors equal to $\alpha=70^{\circ}$ : (a) wider time horizon-illustration of line current flow stretched over time; (b) single welder turn-on instance, zoomed-in view.

The RMS value of the load current fluctuates within the range of $10 \div 12 \mathrm{~A}$, even if the thyristor firing angle is kept constant by the welder control system (due to different welding conditions). The operation of the developed system limits the RMS value of the line current to approx. $2.5 \mathrm{~A}$ (an almost five-fold reduction of the RMS feeder line current). This confirms that the aims set for the apparatus were achieved. 
The operation of the device also reduced rated power, which is required at the point of connection where such loads are used.

Due to the step-down transformer in the structure of the used welding machine, currents are distorted by odd harmonics (especially 3, 5, 7-core saturation effect) [16]. The operation of the filter also limits their content in the line current. The operation with a small value of the firing angle of the thyristor of $\alpha<70^{\circ}$ was omitted due to the fact that the shape of the current was similar to currents occurring during a short circuit, in which an aperiodic DC component could be observed.

The final test of the device is illustrated in Figure 12. The load was turned on for 12 periods of line voltage (twice as long as assumed). During compensation of this load pulse ES capacitance CS was discharged to $35 \%(236 \mathrm{~V})$, however, it is still above the assumed minimum level of $V_{S_{-} \min }=1 / 2 V_{S_{-} \max }$ $=200 \mathrm{~V}$. The obtained results confirm the correct selection of the ES capacity and proper operation of the device.

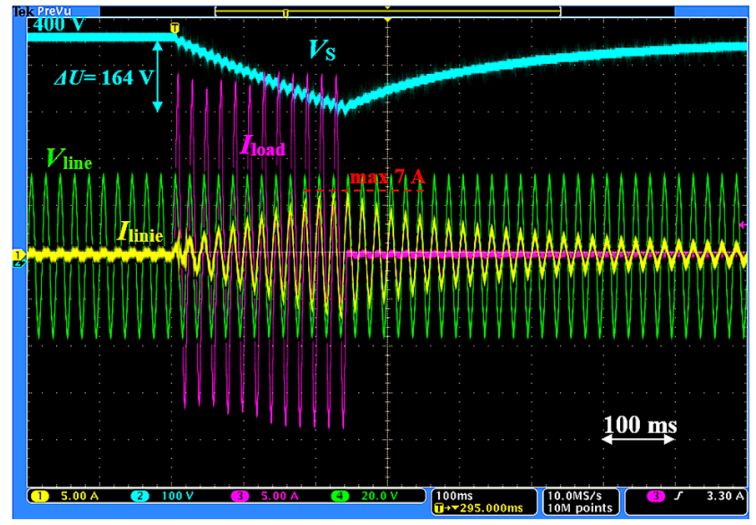

(a)

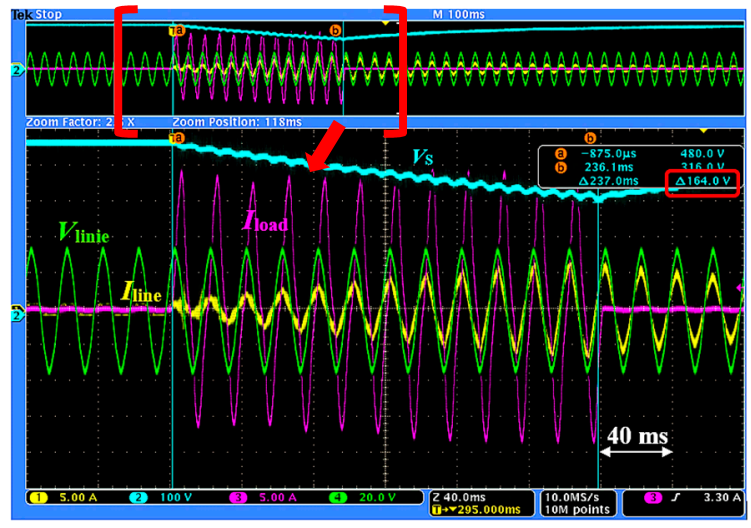

(b)

Figure 12. Measured $I_{\text {line }}, I_{\text {load }}$ currents, line voltage $V_{\text {line }}$ and DC/DC converter voltage $V_{\mathrm{S}}$ during compensation of the load-spot welder, turned on for 12 periods of line voltage $(12 \times 20 \mathrm{~ms})$, firing angle of thyristors equal to $\alpha=70^{\circ}$ : (a) wider time horizon-illustration of line current flow stretched over time; (b) single welder turn-on instance, zoomed-in view.

The comparison of simulation and experimental results can be found in Appendix A, Table A3. In both cases, similar results were obtained, hence the high accuracy of the developed model was confirmed. It should be noted that the control part of the developed model was used directly for digital signal processor (DSP) controller programming and tested in a real-time simulator [36].

\section{Conclusions}

The operating concept of the single-phase active filter with additional energy storage was presented in this paper. Both of them are based on electrolytic capacitors, and have separate DC links. Such a solution provides a good compensation dynamic and allows for the size reduction of filter storage.

The developed device is dedicated to compensation of single-phase loads as, for example, used in the experimental spot welder. Electric spot welders are perfect representatives of nonlinear loads and characterized by intermittent operation. However, this issue also concerns other objects, due to their cyclic operation mode, e.g., crane and lift drives.

The theoretical analyses were used to develop a simulation model of the system in a Matlab and Simulink environment. In the final step, a laboratory model was developed and fully tested.

The simulation and experimental results confirm that the proposed thesis was fully achieved. Its general assumptions included:

- Limitation of the RMS value of the feeder current-the operation of the system reduced it well below the value of the current of the consumer itself, which resulted from load rated active power (a fourfold reduction); 
- The feeder current remaining in a sinusoidal shape (with a dominant 1st harmonic) and in phase with the feeder line voltage.

The proposed solution can produce measurable economic benefits by reducing the rated power necessary to energize periodically operating loads and improving the indicators of electrical energy quality. Moreover, the cross-section areas of power cables can be reduced.

Future work on the issue requires the development of predictive or AI control algorithms dedicated to line current control in a wide time horizon, as well as the optimization of energy storage capacity. In future experiments, the use of other types of energy storage systems, e.g., flying wheels, is also planned. Additionally, the device will be dedicated to three-phase systems and asymmetrical loads.

Author Contributions: Conceptualization, K.S., M.B. and S.P; methodology, K.S., M.B. and S.P.; software, K.S. and M.B.; validation, K.S. and M.B; formal analysis, K.S., M.B. and S.P.; investigation, K.S and M.B.; resources, K.S.; data curation, K.S. and M.B.; writing—original draft preparation, K.S.; writing—review and editing, M.B., S.P.; visualization, K.S.; supervision, M.B. and S.P.; project administration, K.S.; funding acquisition, K.S. and M.B. All authors have read and agreed to the published version of the manuscript.

Funding: This research received no external funding.

Conflicts of Interest: The authors declare no conflict of interest.

\section{Appendix A}

Table A1. Parameters of used controllers.

\begin{tabular}{ccccccc}
\hline & \multicolumn{2}{c}{ DC/DC Converter Controllers } & \multicolumn{3}{c}{ Filter Controllers } \\
\cline { 2 - 7 } Parameters & VC & VC & CC & VC & VC & CC \\
& RU_conv_start & $R U_{-}$conv & RI_conv & RU_filter_start & RU_filter & RI_filter \\
\hline$K_{\mathrm{p}}[-]$ & 0.22 & 0.6 & 50 & 0.09 & 0.03 & 130 \\
$T_{\mathrm{i}}[\mathrm{s}]$ & $20 \times 10^{-3}$ & $11 \times 10^{-3}$ & $5 \times 10^{-3}$ & $10 \times 10^{-3}$ & 40 & $1 \times 10^{-3}$ \\
Saturation upper limit & $2 \mathrm{~A}$ & $20 \mathrm{~A}$ & $500 \mathrm{~V}$ & $7 \mathrm{~A}$ & $15 \mathrm{~A}$ & $500 \mathrm{~V}$ \\
Saturation lower limit & 0 & $-20 \mathrm{~A}$ & 0 & $-7 \mathrm{~A}$ & $-15 \mathrm{~A}$ & $-500 \mathrm{~V}$ \\
\hline
\end{tabular}

Table A2. System parameters and specifications.

\begin{tabular}{ccc}
\hline Symbol & Quantity & Value \\
\hline$L$ & filter input inductance & $4 \mathrm{mH}$ \\
$C_{\mathrm{F}}$ & filter capacitor & $400 \mu \mathrm{F}$ \\
$L_{\mathrm{S}}$ & DC/DC converter inductor & $4 \mathrm{mH}$ \\
$C_{\mathrm{S}}$ & DC/DC converter capacitor & $4700 \mu \mathrm{F}$ \\
$V_{\mathrm{F}}$ & filter reference voltage & $500 \mathrm{~V}$ \\
$V_{\mathrm{S}}$ & DC/DC converter reference voltage & $400 \mathrm{~V}$ \\
$f_{\text {Sw_filter }}$ & filter switching frequency with unipolar modulation & $10 \mathrm{kHz}$ \\
$f_{\text {Sw_conv }}$ & DC/DC converter switching frequency & $10 \mathrm{kHz}$ \\
$I_{S_{-} \text {max }}$ & maximum DC/DC converter current & $20 \mathrm{~A}$ \\
$\Delta I_{\mathrm{S}}$ & DC/DC converter ripple current level & $15 \%$ \\
\hline
\end{tabular}

Table A3. Comparison of simulation and experimental results.

\begin{tabular}{ccc}
\hline Parameter & Simulation & Experiment \\
\hline Startup duration & $1.4 \mathrm{~s}$ & $1.55 \mathrm{~s}$ \\
$i_{\text {line_max }}$ during startup & $7 \mathrm{~A}$ & $7 \mathrm{~A}$ \\
$V_{\text {line_RMS }}$ & $230 \mathrm{~V}$ & $225 \mathrm{~V}$ \\
$i_{\text {load_max }}$ & $20 \mathrm{~A}$ & $22 \mathrm{~A}$ \\
$I_{\text {load_rms_max }}$ & $14 \mathrm{~A}$ & $12 \mathrm{~A}$ \\
$i_{\text {line_max }}$ & $3.2 \mathrm{~A}$ & $4 \mathrm{~A}$ \\
$I_{\text {line_rms_max }}$ & $2.1 \mathrm{~A}$ & $3.3 \mathrm{~A}$ \\
\hline
\end{tabular}




\section{References}

1. Choi, W.; Lee, W.; Han, D.; Sarlioglu, B. New Configuration of Multifunctional Grid-Connected Inverter to Improve both Current-Based and Voltage-Based Power Quality. IEEE Trans. Ind. Appl. 2018, 1, 6374-6382. [CrossRef]

2. Silva, S.A.O.; Negrão, F.A. Single-Phase to Three-Phase Unified Power Quality Conditioner Applied in Single-Wire Earth Return Electric Power Distribution Grids. IEEE Trans. Power Electron. 2018, 33, 3950-3960. [CrossRef]

3. Badoni, M.; Singh, A.; Singh, B. Comparative Performance of Wiener Filter and Adaptive Least Mean Square-Based Control for Power Quality Improvement. IEEE Trans. Ind. Electron. 2016, 63, 3028-3037. [CrossRef]

4. Staudt, V. Fryze-Buchholz-Depenbrock: A time-domain power theory. In Proceedings of the International School on Nonsinusoidal Currents and Compensation, Lagow, Poland, 10-13 June 2008; pp. 1-12.

5. Akagi, H.; Kanazawa, Y.; Nabae, A. Instantaneous reactive power compensators comprising switching devices without energy storage components. IEEE Trans. Ind. Appl. 1984, 2, 625-631. [CrossRef]

6. Dybko, M.A.; Brovanov, S.V. Active power filter with battery energy storage based on NPC inverters. In Proceedings of the 16th International Conference of Young Specialists on Micro/Nanotechnologies and Electron Devices, Erlagol, Russia, 29 June-3 July 2015; pp. 415-421.

7. Alcalá, J.; Cárdenas, V.; Miranda, H.; Pérez-Ramírez, J. A three-phase back-to-back converter for reactive power compensation, current harmonic filtering and active power compensation. In Proceedings of the IEEE Energy Conversion Congress and Exposition, Denver, CO, USA, 15-19 September 2013; pp. 2371-2377.

8. Grabarek, M.; Strzelecki, R. A novel approach to energy safety improvement in the marine power plants with active power surge compensator. In Proceedings of the 2nd Annual Southern Power Electronics Conference, Auckland, New Zealand, 5-8 December 2016; pp. 1-6.

9. Adrikowski, T.; Buła, D.; Pasko, M. Selection of method for reactive power compensation and harmonic filtering in industrial plant. In Proceedings of the Progress in Applied Electrical Engineering, Koscielisko, Poland, 25-30 June 2017; pp. 1-5.

10. Kouchaki, A.; Nymand, M. Analytical Design of Passive LCL Filter for Three-Phase Two-Level Power Factor Correction Rectifiers. IEEE Trans. Power Electron. 2018, 33, 3012-3022. [CrossRef]

11. Buticchi, G.; Consolini, L.; Lorenzani, E. Active Filter for the Removal of the DC Current Component for Single-Phase Power Lines. IEEE Trans. Ind. Electron. 2013, 60, 4403-4414. [CrossRef]

12. Hsu, C.Y.; Wu, H.Y. A new single-phase active power filter with reduced energy-storage capacity. IEEE Proc. Electr. Power Appl. 1996, 143, 25-30. [CrossRef]

13. Tarisciotti, L.; Formentini, A.; Gaeta, A.; Degano, M.; Zanchetta, P.; Rabbeni, R.; Pucci, M. Model Predictive Control for Shunt Active Filters with Fixed Switching Frequency. IEEE Trans. Ind. Appl. 2017, 53, 296-304. [CrossRef]

14. Bosch, S.; Staiger, J.; Steinhart, H. Predictive Current Control for an Active Power Filter with LCL-Filter. IEEE Trans. Ind. Electron. 2018, 65, 4943-4952. [CrossRef]

15. Hou, R.; Emadi, A. Applied Integrated Active Filter Auxiliary Power Module for Electrified Vehicles with Single-Phase Onboard Chargers. IEEE Trans. Power Electron. 2017, 32, 1860-1871. [CrossRef]

16. Sowa, K.; Baszynski, M.; Pirog, S. One phase active filter with energy storage for active power surge compensation in feed line. Arch. Electr. Eng. 2016, 65, 221-234. [CrossRef]

17. Sowa, K.; Baszynski, M.; Pirog, S. Single-phase active filter with an energy storage system used for compensation of active-power fluctuations-simulation results. Prz. Elektrotechniczn. 2017, 93, 260-266.

18. Somayajula, D.; Crow, M.L. An integrated active power filter-ultracapacitor design to provide intermittency smoothing and reactive power support to the distribution grid. IEEE Trans. Sustain. Energy 2014, 5, 1116-1125. [CrossRef]

19. Mutarraf, M.U.; Terriche, Y.; Niazi, K.A.K.; Vasquez, J.C.; Guerrero, J.M. Energy Storage Systems for Shipboard Microgrids-A Review. Energies 2018, 11, 3492. [CrossRef]

20. Oliveira Pinto, J.G.; Macedo, R.; Monteiro, V.; Barros, L.; Sousa, T.; Afonso, J.L. Single-Phase Shunt Active Power Filter Based on a 5-Level Converter Topology. Energies 2018, 11, 1019. [CrossRef]

21. Kumar, V.N.; Panda, G. FPGA Implementation of Power Management Algorithm for Wind Energy Storage System with Kalman Filter MPPT Technique. In Proceedings of the 31st International Conference on VLSI Design and 17th International Conference on Embedded Systems (VLSID), Pune, India, 6-10 January 2018; pp. 449-450. 
22. Qi, W.; Li, S.; Tan, S.; Hui, S.Y. A Single-Phase Three-Level Flying-Capacitor PFC Rectifier without Electrolytic Capacitors. IEEE Trans. Power Electron. 2019, 34, 6411-6424. [CrossRef]

23. Ding, M.; Chen, Z.; Wang, B.; Chen, Z.; Luo, Y.; Zheng, G. Unified control of smoothing out wind power fluctuations and active power filtering by an energy storage system. In Proceedings of the IEEE PES Innovative Smart Grid Technologies, Tianjin, China, 21-24 May 2012; pp. 1-5.

24. Gadalla, A.S.; Yan, X.; Hasabelrasul, H. Performance of the battery energy storage systems based on cascaded H-bridge multilevel converter. J. Eng. 2019, 16, 779-783. [CrossRef]

25. Abeywardana, D.B.W.; Hredzak, B.; Agelidis, V.; Demetriades, G.D. Supercapacitor Sizing Method for Energy-Controlled Filter-Based Hybrid Energy Storage Systems. IEEE Trans. Power Electron. 2017, 32, 1626-1637. [CrossRef]

26. Yan, N.; Zhang, B.; Li, W.; Ma, S. Hybrid Energy Storage Capacity Allocation Method for Active Distribution Network Considering Demand Side Response. IEEE Trans. Appl. Supercond. 2019, 29, 1-4. [CrossRef]

27. Manandhar, U.; Tummuru, N.R.; Kollimalla, S.K.; Ukil, A.; Beng, G.H.; Chaudhari, K.; Kumar, S. Validation of Faster Joint Control Strategy for Battery and Supercapacitor-Based Energy Storage System. IEEE Trans. Ind. Electron. 2018, 65, 3286-3295. [CrossRef]

28. Yan, Z.; Zhang, X.P. General energy filters for power smoothing, tracking and processing using energy storage. IEEE Access 2017, 5, 19373-19382. [CrossRef]

29. Abdeltawab, H.; Mohamed, Y.A.I. Robust Energy Management of a Hybrid Wind and Flywheel Energy Storage System Considering Flywheel Power Losses Minimization and Grid-Code Constraints. IEEE Trans. Ind. Electron. 2016, 63, 4242-4254. [CrossRef]

30. Ye, C.; Yang, J.; Xu, W.; Xiong, F.; Liang, X. A Novel Multi-Unit Out-Rotor Homopolar Inductor Machine for Flywheel Energy Storage System. IEEE Trans. Magn. 2018, 54, 1-5. [CrossRef]

31. Bendib, C.; Kesraoui, M. Wind-Solar Power System associated with Flywheel and Pumped-Hydro Energy Storage. In Proceedings of the 10th International Renewable Energy Congress, Sousse, Tunisia, 26-28 March 2019; pp. 1-6.

32. Baszyński, M.; Piróg, S. A novel speed measurement method for a high-speed BLDC motor based on the signals from the rotor position sensor. IEEE Trans. Ind. Inform. 2014, 10, 84-91. [CrossRef]

33. Thomsen, S.; Hoffmann, N.; Fuchs, F.W. PI control, PI-based state space control, and model-based predictive control for drive systems with elastically coupled loads-A comparative study. IEEE Trans. Ind. Electron. 2011, 58, 3647-3656. [CrossRef]

34. PID Controller Tuning in Simulink. Available online: https://www.mathworks.com/help/slcontrol/gs/ automated-tuning-of-simulink-pid-controller-block.html (accessed on 25 August 2020).

35. Proakis, J.G.; Manolakis, D.K. Digital Signal Processing, 4th ed.; Prentice Hall: Upper Saddle River, NJ, USA, 2007.

36. Sowa, K.; Baszynski, M.; Pirog, S. Single-phase active filter with an energy storage system used for compensation of active-power fluctuations-HIL tests on real time simulator RTS. Prz. Elektrotechniczn. 2019, 95, 200-207.

(C) 2020 by the authors. Licensee MDPI, Basel, Switzerland. This article is an open access article distributed under the terms and conditions of the Creative Commons Attribution (CC BY) license (http://creativecommons.org/licenses/by/4.0/). 